\title{
Transcranial magnetic resonance-guided focused ultrasound for temporal lobe epilepsy: a laboratory feasibility study
}

\author{
Stephen Monteith, MD, ${ }^{1}$ John Snell, PhD, ${ }^{2}$ Mathew Eames, PhD, ${ }^{2}$ Neal F. Kassell, MD, ${ }^{3}$ \\ Edward Kelly, ${ }^{2}$ and Ryder Gwinn, MD' ${ }^{1}$
}

1Department of Neurosurgery, Swedish Neuroscience Institute, Seattle, Washington; ${ }^{2}$ Focused Ultrasound Foundation, Charlottesville; and ${ }^{3}$ Department of Neurosurgery, University of Virginia, Charlottesville, Virginia

\begin{abstract}
OBJECTIVE In appropriate candidates, the treatment of medication-refractory mesial temporal lobe epilepsy (MTLE) is primarily surgical. Traditional anterior temporal lobectomy yields seizure-free rates of $60 \%-70 \%$ and possibly higher. The field of magnetic resonance-guided focused ultrasound (MRgFUS) is an evolving field in neurosurgery. There is potential to treat MTLE with MRgFUS; however, it has appeared that the temporal lobe structures were beyond the existing treatment envelope of currently available clinical systems. The purpose of this study was to determine whether lesional temperatures can be achieved in the target tissue and to assess potential safety concerns.
\end{abstract}

METHODS Cadaveric skulls with tissue-mimicking gels were used as phantom targets. An ablative volume was then mapped out for a "virtual temporal lobectomy." These data were then used to create a target volume on the InSightec ExAblate Neuro system. The target was the amygdala, uncus, anterior $20 \mathrm{~mm}$ of hippocampus, and adjacent parahippocampal gyrus. This volume was approximately $5 \mathrm{~cm}^{3}$. Thermocouples were placed on critical skull base structures to monitor skull base heating.

RESULTS Adequate focusing of the ultrasound energy was possible in the temporal lobe structures. Using clinically relevant ultrasound parameters (power $900 \mathrm{~W}$, duration $10 \mathrm{sec}$, frequency $650 \mathrm{kHz}$ ), ablative temperatures were not achieved (maximum temperature $46.1^{\circ} \mathrm{C}$ ). Increasing sonication duration to $30 \mathrm{sec}$ demonstrated lesional temperatures in the mesial temporal lobe structures of interest (up to $60.5^{\circ} \mathrm{C}$ ). Heating of the skull base of up to $24.7^{\circ} \mathrm{C}$ occurred with 30-sec sonications.

CONCLUSIONS MRgFUS thermal ablation of the mesial temporal lobe structures relevant in temporal lobe epilepsy is feasible in a laboratory model. Longer sonications were required to achieve temperatures that would create permanent lesions in brain tissue. Heating of the skull base occurred with longer sonications. Blocking algorithms would be required to restrict ultrasound beams causing skull base heating. In the future, MRgFUS may present a minimally invasive, nonionizing treatment of MTLE.

http://thejns.org/doi/abs/10.3171/2015.10.JNS1542

KEY WORDS focused ultrasound; epilepsy; temporal lobe; epilepsy treatment; magnetic resonance-guided focused ultrasound; MRgFUS

I $\mathrm{N}$ appropriate candidates, the treatment of medicationrefractory temporal lobe epilepsy is primarily surgical. Traditional anterior temporal lobectomy yields seizurefree rates of $60 \%-70 \%$, or possibly higher. ${ }^{1,9,19}$ Selective amygdalohippocampectomy has been used in an effort to minimize temporal lobe disruption, minimize vascular injury, and decrease language complications. Similar results have been achieved with this technique. ${ }^{12}$ More recently, minimally invasive techniques to treat mesial temporal lobe epilepsy (MTLE) have been explored. Stereotactic radiosurgery has been attempted but not widely adopted due to decreased levels of seizure control compared with surgery and concerns regarding treatment volumes and swelling of the temporal lobe. ${ }^{20,23}$ Image-guided treatments with radiofrequency ablation and laser-tipped devices have also been investigated in trials with encouraging early results..$^{10,11,24}$

Transcranial magnetic resonance-guided focused ul- 
trasound (MRgFUS) is a rapidly emerging technology that has already been used effectively in the treatment of Parkinson's disease, essential tremor, obsessive-compulsive disorder, and chronic neuropathic pain. , $^{2,14,16,22,25}$ The device (InSightec ExAblate Neuro) uses a $650-\mathrm{kHz}$ phased array transducer to send 1024 beams of converging ultrasound energy onto a focal point deep within the brain. At the focal point there is heating, which is monitored by real-time MR thermometry to confirm thermal ablation at the targeted point. Until now it was felt that the mesial temporal lobe was beyond the viable treatment envelope of the device and that a clinically relevant temperature rise could not be achieved in the target tissue. The goal of this experiment was to determine whether lesional temperatures could be achieved in the target tissue. Heating of skull base areas of interest was also performed to assess potential safety concerns.

\section{Methods}

Three cadaveric skulls were used for the experiments. Acquisition of cadaveric material was performed in accordance with standard institutional policy for human tissue. Skulls were debrided of all soft tissue and degassed using an industrial degassing chamber filled with degassed water.

\section{Imaging Protocol}

Prior to removal of soft tissue, including the brain, thin-slice $(0.5-\mathrm{mm})$ CT scans of the head with bone windows were obtained to enter into the software system's 3D correction algorithm for skull aberration and attenuation. This algorithm allows the beams to converge on a highly focused central point deep within the brain. Axial and coronal $\mathrm{T} 2$-weighted spin echo images of the brain were obtained in a 3T MRI scanner (General Electric); 3D reconstructions were performed and input into neuronavigation software used for surgical planning for tem- poral lobectomy surgery (BrainLab). An ablative volume was then mapped out for a "virtual temporal lobectomy." These data were then used to create a target volume on the InSightec ExAblate system. The target was the amygdala, uncus, anterior $20 \mathrm{~mm}$ of hippocampus, and adjacent parahippocampal gyrus. This volume was approximately $5 \mathrm{~cm}^{3}$ (Fig. 1).

\section{MRgFUS Protocol}

To reach the mesial temporal lobe structures the skull was pinned low using the stereotactic frame (Radionics). Occipital pins were placed below the level of the external occipital protuberance. The transducer was tilted backward $15^{\circ}$ to allow advancement of the head deeper into the transducer and thereby provide access to the deeper structures of the brain. The transducer was adjusted laterally so that the mesial temporal lobe structures were centered over the natural focus (center) of the transducer. The degassed skull had been filled with a liquid molded tissuemimicking gel, which was fitted to fill the volume of the skull by pouring it in liquid form and allowing it to solidify for 24 hours. The skull was degassed separately and the skull and gel were assembled just prior to installation in the transducer. Once in position, the transducer was filled with degassed water (dissolved $\mathrm{O}_{2}$ less than $1.2 \mathrm{ppm}$ ) and the skull/gel setup was again allowed to de-gas. Confirmatory $\mathrm{T} 2$-weighted images were then obtained and overlaid with the CT scan and treatment-planning MRI. The CT imaging bone correction algorithm was registered and applied to the MR images to perform skull acoustic aberration correction. Real-time MR thermometry was used to confirm accurate targeting in 2 frequency directions with low-energy sonications $(150 \mathrm{~W}, 10 \mathrm{sec}, 650 \mathrm{kHz})$. Treatment sonications were then performed throughout the treatment volume (Fig. 2) and the temperatures at the target were recorded using real-time MR thermometry in the thermoreactive gel (Fig. 3). The perimeter and central

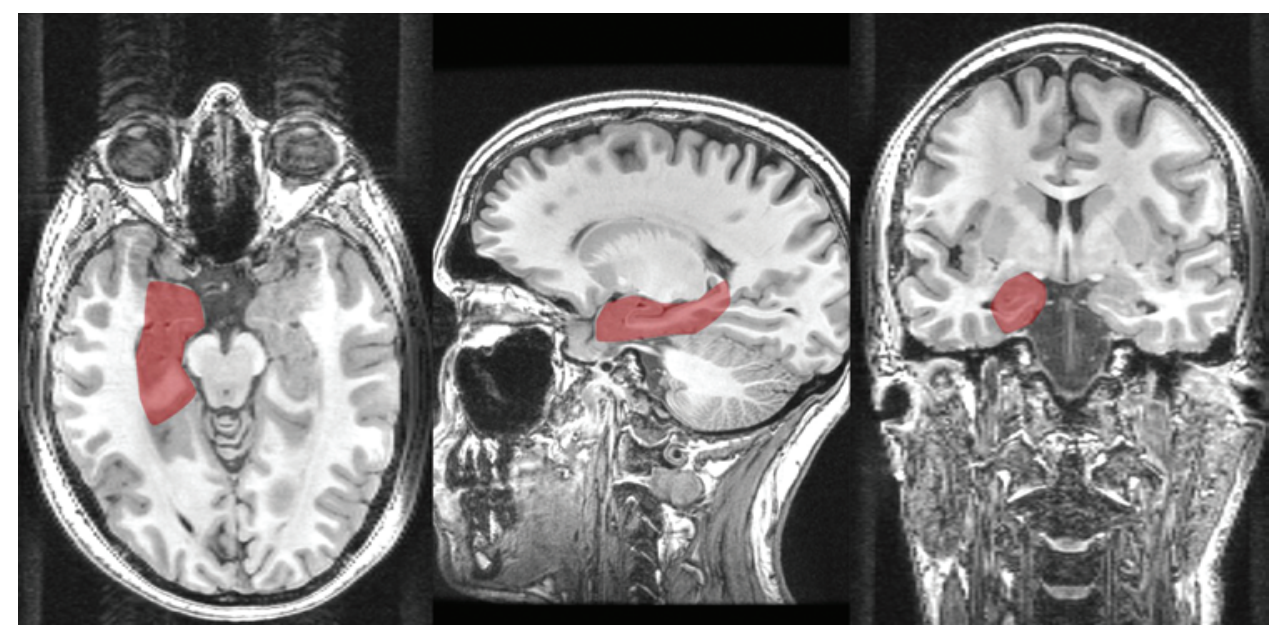

FIG. 1. Axial, sagittal, and coronal T1-weighted MR images for target planning (shaded area). Target structures for simulated ablation include the amygdala, uncus, hippocampus, and parahippocampal gyrus. Coronally acquired slices were used to create a treatment plan for the amygdala and uncus. The upper one-third of the amygdala, corresponding to the portion above the plane of the choroidal point, and the horizontal portion of the middle cerebral artery were not targeted. The hippocampus and parahippocampal gyrus were targeted along the head and body of the hippocampus using axial and coronal MRI slices back to the level of the superior colliculus. Figure is available in color online only. 


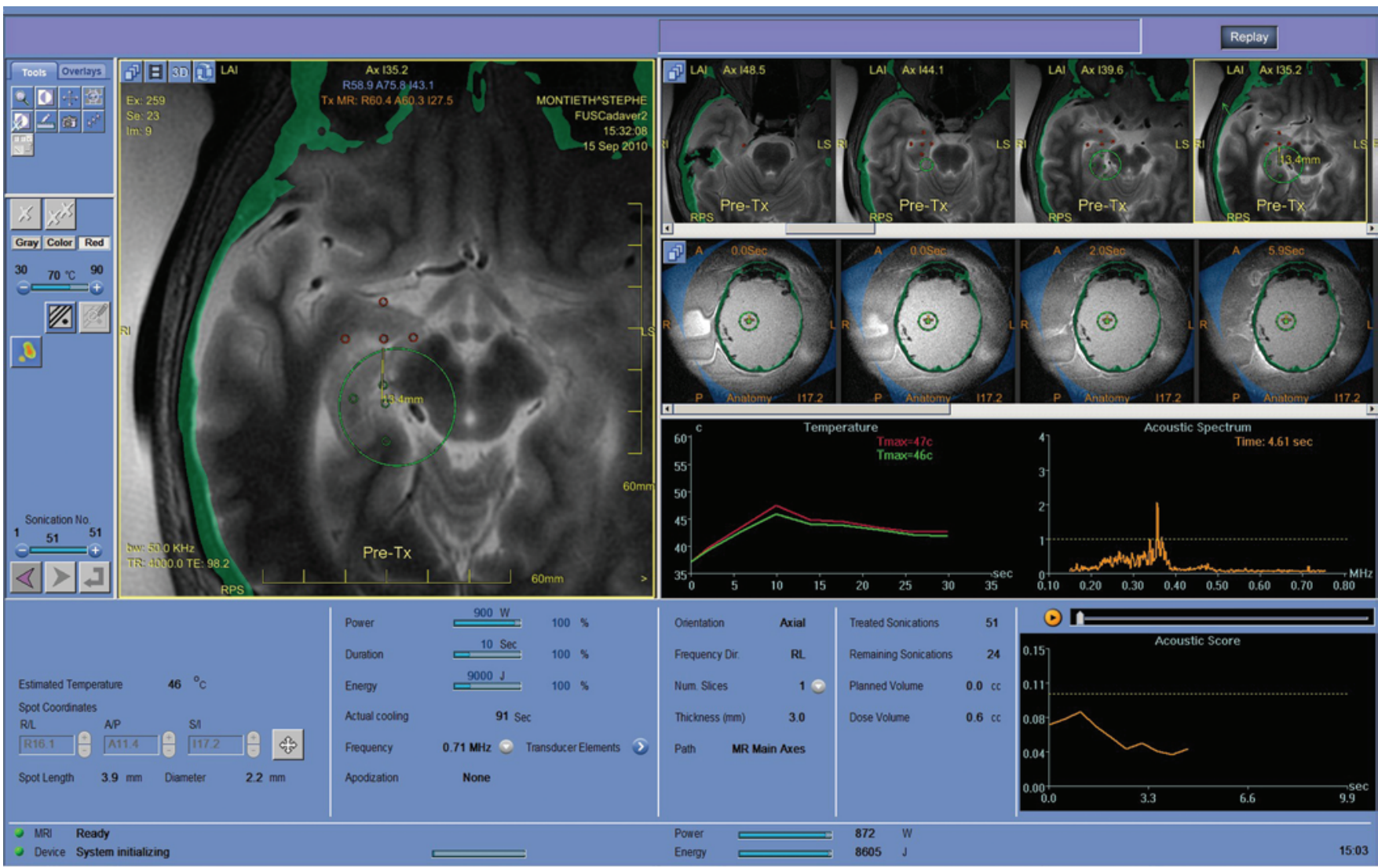

FIG. 2. Intraprocedural T2-weighted planning MRI. To test feasibility of the treatment envelope, sonications are spaced throughout the target volume to be ablated. The green circle indicates the area that can be sonicated for a particular transducer position. Note that the transducer has been moved posteriorly to cover the entire treatment volume after treating the anterior targets (small red circles). Figure is available in color online only.

core of the treatment volume were targeted to determine if the entire treatment volume could be effectively heated to lesional temperatures. The software assumes a baseline temperature of $37^{\circ} \mathrm{C}$.

The skull base had been fitted with thermocouples using cyanoacrylate adhesive to record the temperature rise at skull base locations of interest. MR-compatible thermocouples recorded temperature every $50 \mathrm{msec}$ at the following locations: 1) optic canal, 2) carotid canal, 3) temporal fossa, 4) foramen ovale, 5) internal acoustic canal, and 6) petrous ridge. Temperatures were recorded at the focal point of heating in the gel with MR thermometry and at the skull base with thermocouples. Sonications were repeated and the results averaged (Fig. 4).

\section{Results}

Adequate focusing of the ultrasound transducer to cover the treatment volume was possible in all specimens. The thalamus was initially targeted in all specimens to act as an internal control. The thalamus was chosen as it is a target that has been used clinically with dependable results. This internal control was used to offset inherent differences in skull parameters and gel thermoreactivity variance between specimens. In all cases a thalamic "lesion" of approximately $51^{\circ} \mathrm{C}$ with standard clinically relevant energy doses $(900 \mathrm{~W}, 10 \mathrm{sec}, 650 \mathrm{kHz})$ could be achieved prior to treating the temporal target. Parameters of $900 \mathrm{~W}, 10 \mathrm{sec}$ $(650 \mathrm{kHz})$ and $900 \mathrm{~W}, 30 \mathrm{sec}(650 \mathrm{kHz})$ were used. Results are displayed as averages. The treatment volume was targeted with sonications until the extremes of the treatment volume as well as the core were treated according to the ExAblate software. The spot location was recorded by the MRI scanner as a value in 3D space (anterior/posterior, left/right, superior/inferior).

With a power of $900 \mathrm{~W}$ for $10 \mathrm{sec}$, a focal spot could be created at the target at all of the locations. The temperature rise, however, would be inadequate to cause a permanent lesion in patients. The maximum temperature rise with these parameters was $9.1^{\circ} \mathrm{C}$ (Table 1). The maximum temperature rise of skull base bony areas of interest was $14.2^{\circ} \mathrm{C}$ at the petrous ridge using these parameters.

With a power of $900 \mathrm{~W}$ for $30 \mathrm{sec}$, higher temperatures at focus could be achieved. Temperatures from $53.3^{\circ} \mathrm{C}$ to $60.5^{\circ} \mathrm{C}$ were achieved at target (assuming a $37^{\circ} \mathrm{C}$ baseline), significantly higher than the temperatures achieved at the thalamus with clinically used energy levels $(900 \mathrm{~W}$ for $10 \mathrm{sec}, 50.8^{\circ} \mathrm{C}$ temperature rise at the thalamus). Temperatures were higher at the optic canal (difference of up to $24.7^{\circ} \mathrm{C}$ ) as well as the internal auditory canal (difference of up to $23.5^{\circ} \mathrm{C}$ ) (Table 2). 

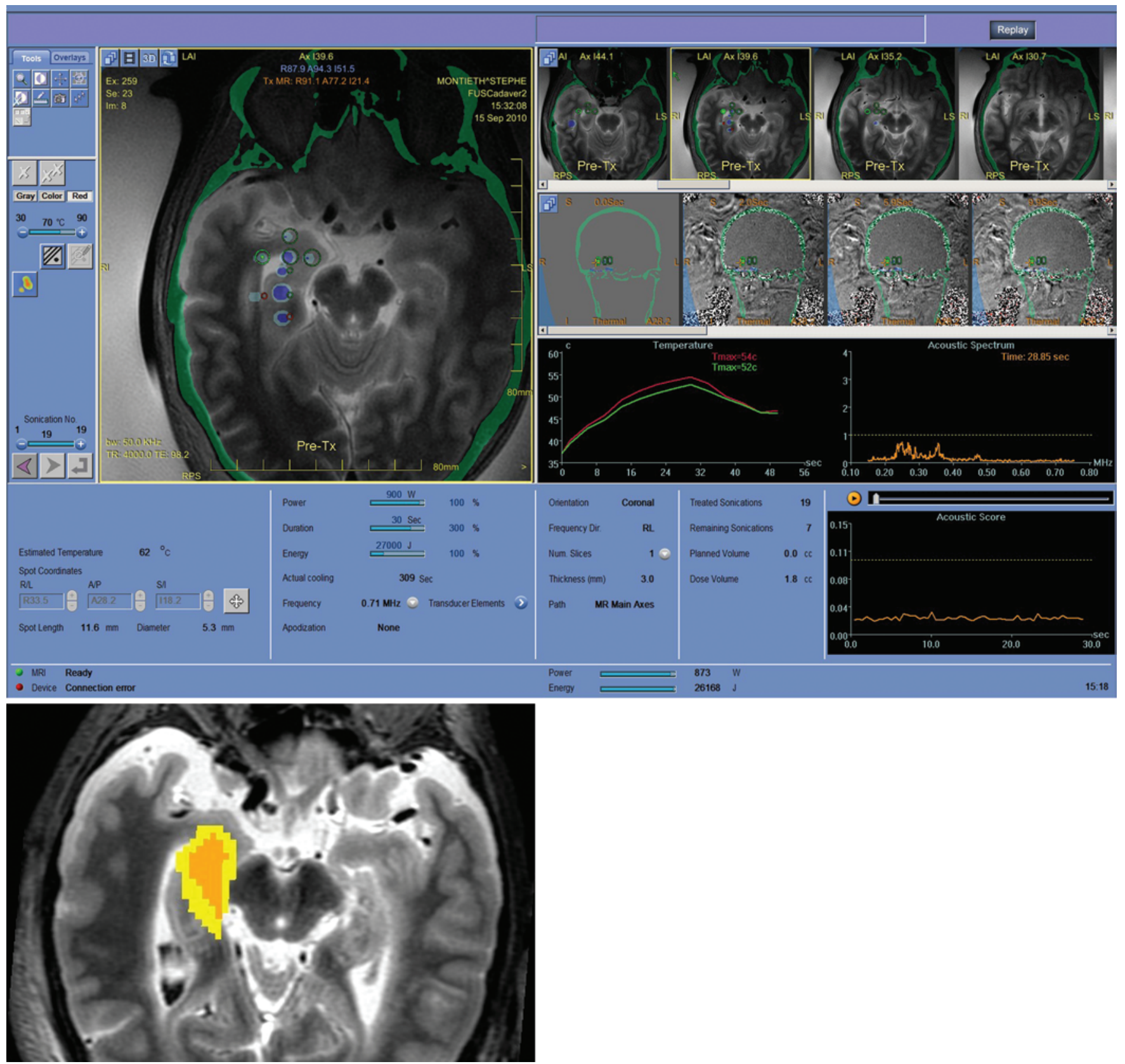

FIG. 3. Upper: Intraprocedural T2-weighted planning MRI. Blue spots indicate treated sonications (left panel). The current sonication is the bright green circle. The MR image is overlaid to demonstrate anatomical structures. The upper right panel shows the current sonication. The middle right panel demonstrates the temperature rise at the target and is acquired by the MRI every 3 seconds during the sonication process. The lower right panel shows that the current sonication has created a lesion of peak temperature of $54^{\circ}$ in the thermoreactive gel (baseline of $37^{\circ}$ is assumed). Lower: Preoperative T2-weighted planning MRI. Representative slice of interpolation of temperature rise data for each series of sonications demonstrates that the treatment volume can be effectively heated to clinically significant temperatures using longer sonications (power $900 \mathrm{~W}$, time $30 \mathrm{sec}$, frequency $650 \mathrm{kHz}$ ). The yellow and orange area depicts the targeted treatment volume and shows temperatures that would be predicted to achieve thermal ablation. Figure is available in color online only.

\section{Discussion}

The field of MRgFUS is a rapidly emerging area of neurosurgery. Treatments for essential tremor, Parkinson's disease, obsessive-compulsive disorder, neuropathic pain, and brain tumors have all been the subject of recent clinical trials. ${ }^{4,14,16,25}$ There is intense interest in the neurosurgical community to determine whether MRgFUS could be used to treat various forms of epilepsy, including epileptogenic hypothalamic hamartoma, epileptic tuberous sclerosis lesions, and MTLE. Central lesions from tuberous sclerosis and hypothalamic hamartoma are clearly within the current device treatment envelope and represent the low-hang- 


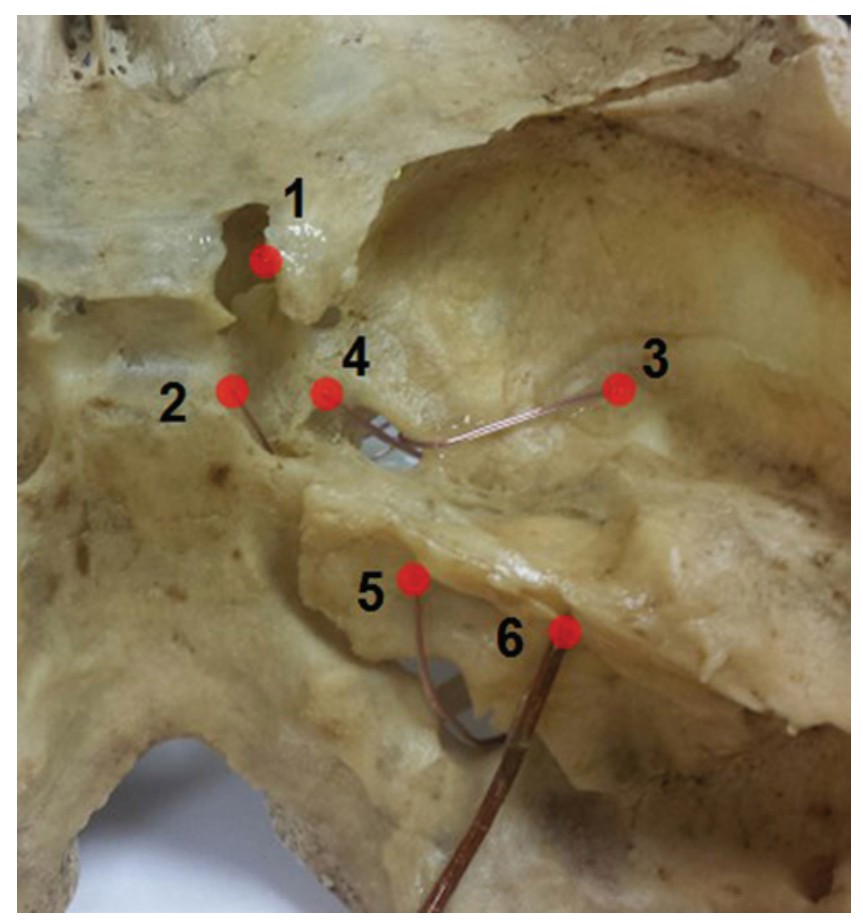

FIG. 4. Photograph showing location of thermocouples, which are placed to acquire skull base temperature rise every 50 msec during the sonication process. Areas of interest are 1) optic canal, 2) carotid canal, 3) temporal fossa, 4) foramen ovale, 5) internal acoustic canal, 6) petrous ridge. Figure is available in color online only.

ing fruit for non-ionizing, minimally invasive treatment of these forms of epilepsy with MRgFUS. Their central location puts the lesions at the optimum ultrasonic advantage when considering the physical and electromechanical attributes of current hemispheric ultrasound transducer arrays. Stereotactic radiosurgery has been used for the treatment of these lesions, but there is some concern about the use of radiation in the developing brain. ${ }^{21} \mathrm{MRgFUS}$ may represent an attractive option for these lesions as the ultrasound energy is non-ionizing. MTLE is more challenging due to the structures involved being low and lateral when considering the treatment envelope of the current clinically used device. The ultrasound waves have to be redirected more drastically by the machine to focus them on the treatment spot. A large proportion of the 1024 ultrasound elements in the transducer are not optimally transmitting energy to the focal spot due to acute incident angles with the skull. The incident angle refers to the angle at which the ultrasound beam hits the skull. Maximal electromechanical efficiency is achieved if the beam hits directly perpendicular to the skull, whereas beams hitting at an angle have to be electrically steered to focus on the focal point. This electrical steering decreases the efficiency of the ultrasound beam and decreases the amount of energy transferred through the skull to the target. Despite this, the ability to target deep and lateral targets within the brain has been demonstrated in laboratory studies but not in a clinical setting. ${ }^{16,17}$ This study demonstrates heating of the mesial temporal lobe structures of up to $60.5^{\circ} \mathrm{C}$ using longer sonication durations $(30 \mathrm{sec})$. Ablative temperatures sufficient for thermal coagulation are achieved at a peak temperature of approxi- mately $55^{\circ} \mathrm{C}$ or 240 equivalent minutes at $43^{\circ} \mathrm{C}$ (thermal equivalent minutes [TEM] 43)..$^{8,13,18}$ The sharpness of the thermal lesion has been consistently demonstrated in clinical studies. ${ }^{4,25}$ Animal studies have demonstrated focused ultrasound lesions with similar histological appearances to radiofrequency ablation and sharper margins than Gamma Knife radiosurgery. ${ }^{5}$ To that end, the energy drop-off from target tissue temperatures to adjacent brainstem structures and the third cranial nerve is such that heating would not be expected to occur at these sites. Animal studies have demonstrated a threshold of $50^{\circ} \mathrm{C}$ to induce thermal necrosis of optic nerves in swine. ${ }^{6}$ While the exact thermal thresholds of human cranial nerves are not know at this time it would be prudent during clinical treatments to pay careful attention to the MR thermometry readings in the areas with cranial nerves present and avoid high temperatures. Avoidance of ultrasound energy to the posterior cerebral artery is also critically important. Animal studies have noted mechanical effects, including vessel disruption, as a result of focused ultrasound exposure, even without the presence of a temperature rise. Further studies suggest that this phenomenon is therefore a mechanical effect of the ultrasound rather than purely thermal. ${ }^{7}$ Toward the periphery of the target volume, the temperature rise tends to drop off due to the amount of electrical steering required by the transducer to phase-correct the beams. In addition, there is a mechanical disadvantage of the transducer location with inefficient incident angles against the skull. Parameter optimization at the edge of the treatment target is needed to mitigate this drop-off. If peak temperatures greater than $55^{\circ} \mathrm{C}$ cannot be achieved, several sonications at lower temperature may be required to deposit enough energy to ablate the tissue. Such approaches may be time consuming, and the associated treatment effect may be less predictable than that of a single, effective high-temperature sonication. Further investigation of these strategies is warranted.

Our results demonstrate that lower sonication durations do not appear to deposit enough energy at the target to induce the clinically relevant thermal deposition required to create a permanent lesion. With longer sonication durations there is unfortunately a cost; and there is more heating of the skull base (Fig. 5). These "areas of concern" heat because of the "far field" of the ultrasound beams that have passed through the focus already and hit bony structures distant to the target. Blocking algorithms can mitigate this phenomenon by the creation of "no pass regions." Previous studies have demonstrated a significant drop in collateral skull base heating without a significant drop in target temperature when the trigeminal nerve was targeted. ${ }^{17}$ Further optimization of the treatment plan would be required in the clinical setting.

There are several limitations in using a cadaveric skull phantom. The temperature in the MRI room is $16^{\circ} \mathrm{C}$, which is significantly lower than body temperature. The phantoms do not demonstrate heat exchange, which is seen in patients. There is no CSF flow and no blood flow through the brain and blood vessels. The bone of the skull base is also rich in blood flow and therefore has a heat sink effect. This is advantageous in that there is no significant effect on the target temperature, but there is a decrease 
TABLE 1. Results achieved with a low-duration sonication algorithm using parameters typically used in clinical trials*

\begin{tabular}{|c|c|c|c|c|c|c|c|c|c|c|c|c|}
\hline \multirow[b]{2}{*}{ Sonication } & \multirow[b]{2}{*}{ Power (W) } & \multirow[b]{2}{*}{ Duration (sec) } & \multirow[b]{2}{*}{ Energy $(\mathrm{J})$} & \multirow{2}{*}{$\begin{array}{l}\text { Sonication Location } \\
\text { (rt/lt, A/P, S/l) }\end{array}$} & \multirow{2}{*}{$\begin{array}{c}\operatorname{Tmax} \\
\left({ }^{\circ} \mathrm{C}\right)\end{array}$} & \multirow{2}{*}{$\begin{array}{l}\text { T Rise } \\
\left({ }^{\circ} \mathrm{C}\right)\end{array}$} & \multicolumn{6}{|c|}{ Skull Base Area of Interest† } \\
\hline & & & & & & & 1 & 2 & 3 & 4 & 5 & 6 \\
\hline 1 & 900 & 10 & 9000 & $17.97,27.58,-27.28$ & 44.7 & 7.7 & 3.4 & 1.5 & 5.9 & 2.0 & 1.5 & 1.5 \\
\hline 2 & 900 & 10 & 9000 & $18.69,37.48,-27.87$ & 43.8 & 6.8 & 2.6 & 1.5 & 4.0 & 3.1 & 2.7 & 1.4 \\
\hline 3 & 900 & 10 & 9000 & $9.73,29.56,-26.82$ & 43.7 & 6.7 & 2.5 & 1.9 & 2.5 & 2.2 & 1.3 & 2.3 \\
\hline 4 & 900 & 10 & 9000 & $18.03,18.27,-26.77$ & 44.8 & 7.8 & 0.6 & 1.2 & 2.1 & 2.2 & 2.8 & 3.1 \\
\hline 5 & 900 & 10 & 9000 & $28.44,27.07,-27.97$ & 43.8 & 6.8 & 2.5 & 1.4 & 4.7 & 2.4 & 1.4 & 4.7 \\
\hline 6 & 900 & 10 & 9000 & $18.82,27.83,-22.83$ & 45.0 & 8.0 & 1.3 & 1.5 & 1.4 & 2.1 & 2.7 & 2.9 \\
\hline 7 & 900 & 10 & 9000 & $18.82,36.69,-23.32$ & 44.3 & 7.3 & 2.2 & 0.9 & 4.3 & 0.8 & 2.0 & 5.1 \\
\hline 8 & 900 & 10 & 9000 & $19.07,16.67,-22.24$ & 43.2 & 6.2 & 5.6 & 1.7 & 2.7 & 3.4 & 3.2 & 2.3 \\
\hline 9 & 900 & 10 & 9000 & $28.11,27.85,-23.48$ & 43.9 & 6.9 & 4.5 & 4.2 & 1.5 & 0.6 & 1.1 & 2.1 \\
\hline 10 & 900 & 10 & 9000 & $18.14,27.25,-31.79$ & 45.1 & 8.1 & 2.4 & 6.3 & 3.6 & 1.2 & 1.6 & 3.8 \\
\hline 11 & 900 & 10 & 9000 & $17.10,36.51,-32.22$ & 43.1 & 6.1 & 2.2 & 1.9 & 2.6 & 1.2 & 2.2 & 7.0 \\
\hline 12 & 900 & 10 & 9000 & $11.14,27.64,-31.33$ & 44.5 & 7.5 & 3.3 & 6.3 & 1.6 & 1.1 & 1.8 & 4.0 \\
\hline 13 & 900 & 10 & 9000 & $18.41,19.17,-31.36$ & 43.1 & 6.1 & 2.0 & 3.9 & 5.5 & 8.8 & 7.7 & 13.0 \\
\hline 14 & 900 & 10 & 9000 & $26.27,27.54,-32.37$ & 44.1 & 7.1 & 2.7 & 2.5 & 4.0 & 0.1 & 0.4 & 0.3 \\
\hline 15 & 900 & 10 & 9000 & $17.25,26.22,-36.19$ & 46.1 & 9.1 & 0.0 & 0.0 & 0.0 & 1.1 & 1.1 & 3.2 \\
\hline 16 & 900 & 10 & 9000 & $18.58,12.24,-21.96$ & 44.4 & 7.4 & 1.2 & 1.0 & 3.0 & 1.5 & 2.5 & 4.1 \\
\hline 17 & 900 & 10 & 9000 & $18.54,3.14,-21.46$ & 43.7 & 6.7 & 0.8 & 1.2 & 3.2 & 2.2 & 5.7 & 14.2 \\
\hline 18 & 900 & 10 & 9000 & $26.32,13.49,-22.57$ & 43.7 & 6.7 & 1.2 & 2.0 & 9.6 & 2.0 & 2.3 & 12.0 \\
\hline 19 & 900 & 10 & 9000 & $16.21,9.80,-26.18$ & 44.4 & 7.4 & 1.1 & 1.8 & 3.8 & 1.0 & 1.4 & 3.9 \\
\hline 20 & 900 & 10 & 9000 & $15.81,2.83,-25.77$ & 43.5 & 6.5 & 3.0 & 3.5 & 2.7 & 1.5 & 3.8 & 5.3 \\
\hline 21 & 900 & 10 & 9000 & $24.09,11.20,-26.80$ & 43.2 & 6.2 & 2.9 & 1.2 & 2.0 & 3.1 & 2.4 & 1.5 \\
\hline
\end{tabular}

$\mathrm{A}=$ anterior; $\mathrm{I}=$ inferior; $\mathrm{P}=$ posterior; $\mathrm{S}=$ superior; $\mathrm{T}=$ temperature.

* The results demonstrate the inability to heat temporal lobe structures to high enough temperatures to effectively ablate tissue (requires a temperature of $\left.55^{\circ} \mathrm{C}\right)$.

$\dagger$ Numbers 1-6 represent skull base areas of interest. Locations are shown in Figure 4.

in collateral heating at the far-field sites due to this heat sink effect of moving liquid. There is also an advantage of a large heat sink effect from high-volume blood vessels, such as the venous sinuses, as well as high-flow systems, such as the internal carotid artery. In addition, there is no accounting for blood flow in the scalp. While we did not see significant heating of the skull surface, without a scalp it is difficult to determine whether the longer heating durations could be tolerated by patients. Longer sonications may induce heating in the scalp and dura that was not readily detectable in this study. Such heating could be measured in the clinical setting, should it occur, using realtime MR thermometry. If heating were to occur, multiple shorter sonications could be used to deposit the same thermal dose without these effects.

There are several limitations to the use of MRgFUS for

TABLE 2. Results obtained with long-duration sonication algorithm $(30 \mathrm{sec})$ using power parameters typically used in clinical trials*

\begin{tabular}{|c|c|c|c|c|c|c|c|c|c|c|c|c|}
\hline \multirow[b]{2}{*}{ Sonication } & \multirow{2}{*}{$\begin{array}{l}\text { Power } \\
\text { (W) }\end{array}$} & \multirow{2}{*}{$\begin{array}{l}\text { Duration } \\
\text { (sec) }\end{array}$} & \multirow{2}{*}{$\begin{array}{l}\text { Energy } \\
(\mathrm{J})\end{array}$} & \multirow{2}{*}{$\begin{array}{l}\text { Sonication Location } \\
\text { (rt/lt, A/P, S/l) }\end{array}$} & \multirow{2}{*}{$\begin{array}{l}\text { Tmax } \\
\left({ }^{\circ} \mathrm{C}\right)\end{array}$} & \multirow{2}{*}{$\begin{array}{c}\text { Average } \\
\text { T Rise }\left({ }^{\circ} \mathrm{C}\right)\end{array}$} & \multicolumn{6}{|c|}{ Skull Base Area of Interest } \\
\hline & & & & & & & 1 & 2 & 3 & 4 & 5 & 6 \\
\hline $1 \dagger$ & 900 & 10 & 9000 & $16.75,12.99,-3.76$ & 50.7 & 13.7 & 0.0 & 0.0 & 0.0 & 0.0 & 0.0 & 0.0 \\
\hline $2 \dagger$ & 900 & 10 & 9000 & $23.64,14.87,-17.79$ & 50.8 & 13.8 & 0.0 & 0.0 & 0.0 & 0.0 & 0.0 & 0.0 \\
\hline 3 & 900 & 20 & 18,000 & $23.64,14.87,-17.79$ & 53.3 & 16.3 & 3.5 & 8.5 & 23.1 & & & \\
\hline 4 & 900 & 30 & 27,000 & $23.64,14.87,-17.79$ & 57.7 & 20.7 & 2.7 & 5.6 & 11.7 & & & \\
\hline 5 & 900 & 30 & 27,000 & $23.10,22.97,-17.56$ & 55.5 & 18.5 & 4.5 & 4.9 & 8.2 & 7.4 & 7.1 & 6.8 \\
\hline 6 & 900 & 30 & 27,000 & $22.87,5.30,-17.95$ & 56.8 & 19.8 & 3.5 & 3.1 & 14.0 & 3.3 & 5.4 & 9.0 \\
\hline 7 & 900 & 30 & 27,000 & $32.86,13.43,-18.51$ & 53.1 & 16.1 & 24.7 & 11.1 & 11.6 & 5.1 & 4.2 & 12.9 \\
\hline 12 & 900 & 30 & 27,000 & $22.80,28.29,-17.42$ & 60.5 & 23.5 & 1.5 & 1.6 & 7.2 & 3.1 & 4.1 & 5.7 \\
\hline 14 & 900 & 30 & 27,000 & $23.02,35.99,-17.26$ & 56.7 & 19.7 & 1.9 & 2.0 & 9.8 & 2.5 & 2.1 & 9.7 \\
\hline 17 & 900 & 30 & 27,000 & $14.66,27.80,-16.82$ & 55.7 & 18.7 & 16.2 & 5.0 & 18.8 & 1.7 & 2.5 & 8.0 \\
\hline 18 & 900 & 30 & 27,000 & $33.49,28.18,-18.2$ & 54.9 & 17.9 & 3.3 & 6.5 & 23.5 & 4.9 & 6.2 & 10.9 \\
\hline
\end{tabular}

* The results demonstrate the ability to heat temporal lobe structures to high enough temperatures to effectively ablate tissue (requires temperature of $55^{\circ} \mathrm{C}$ ).

$\dagger$ Test sonications done at lower energy and used as an internal control to confirm expected control temperature rises for a given thermal dose. 


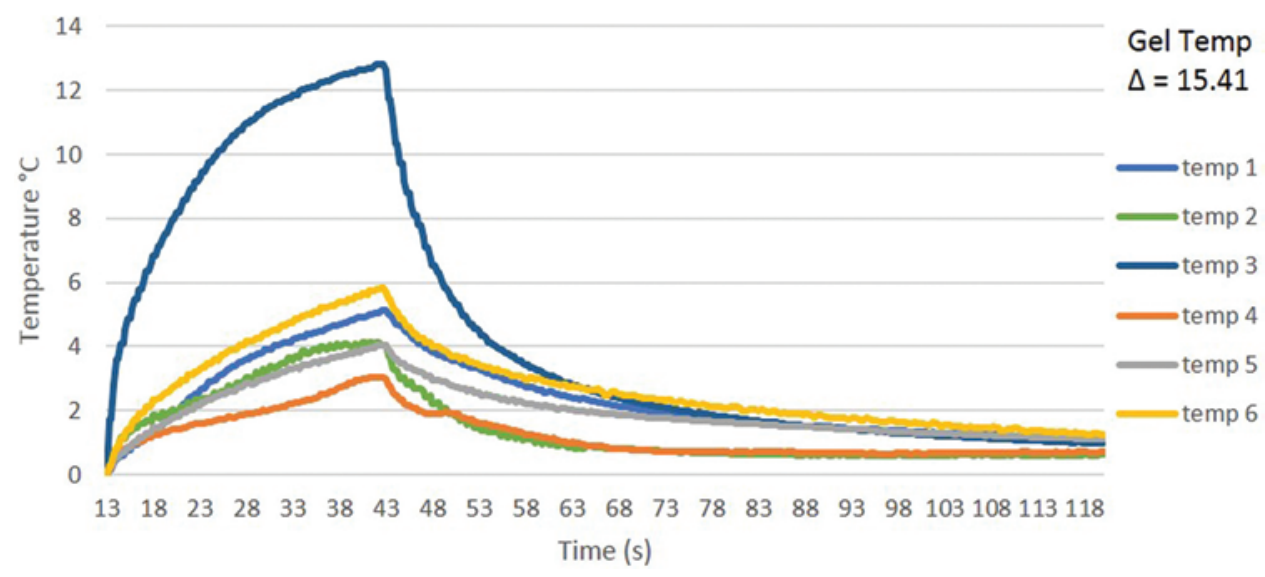

FIG. 5. Graph showing the temperature rise of thermocouples placed on the skull during sonications. Thermocouples were placed to monitor temperature rises at areas of concern (see Fig. 4). As an example, in this sonication ( $900 \mathrm{~W}, 30 \mathrm{sec})$ a temperature rise of $15.4^{\circ} \mathrm{C}$ was achieved at target. However, there was a temperature rise of $12.7^{\circ} \mathrm{C}$ at the internal acoustic canal (thermocouple 5 on Fig. 4). Such heating of the skull base areas of concern can be mitigated by employing blocking algorithms. These algorithms turn off ultrasound beams that create a "shadow" of energy distal to the target and heat the skull base and critical structures such as cranial nerves. temp $=$ temperature. Figure is available in color online only.

the treatment of MTLE. The amygdala, anterior $20 \mathrm{~mm}$ of hippocampus, and adjacent parahippocampal gyrus represent a treatment volume of approximately $5 \mathrm{~cm}^{3}$. Based on our experience, it would require approximately 4-6 hours to treat the entire treatment volume given current limitations on the technology, including cooling of the scalp from the circulating cold water after each sonication, and sonication ablation volume (which is dependent on energy delivered). One of the benefits of MRgFUS is that treatments could be staged, as there is no dose-accumulation effect, in contrast to radiation-based treatments. It is likely that a staged approach would mitigate issues associated with edema due to cell death, as smaller areas could be targeted each time. In addition, if a positive clinical result was obtained after a first procedure, then further unnecessary ablation might not be required. It is likely that the time constraints will require a novel treatment approach. Rather than treating a total volume, a checkerboard or perimeter ablation approach may be more efficient and achieve the same result of surgical disconnection. Other barriers to adoption include the requirement to physically move the transducer to cover the entire treatment volume. This again increases the amount of time that the patient is required to remain on the treatment table. It would be critical to choose patients who would have a high likelihood of success and would be able to tolerate a potentially long procedure.

Minimally invasive approaches to MTLE have shown promise. Both radiofrequency ablation and the more recent use of laser therapies have demonstrated the utility of a minimally invasive approach. ${ }^{3,24}$ Willie et al. treated 13 patients with laser amygdalohippocampectomy, ablating a mean of $60 \%$ of the amygdalohippocampal complex. At a median follow-up duration of 14 months, meaningful seizure reduction had been achieved in $77 \%$ of the cases and seizure freedom in 54\%. Variances in ablation volume did not correlate with clinical outcome. While there was no complication from the laser therapy itself, 1 patient developed a visual field deficit as a result of deviated insertion of the aligning rod. ${ }^{24}$ The limitation of these techniques is that they are still invasive and require a surgical procedure involving the passage of an instrument into the target area. Trajectory-related side effects, such as visual field deficits, have been reported. ${ }^{15,24}$ In 1 study, laser amygdalohippocampectomy was associated with improved object and naming recognition compared with standard surgical treatment. ${ }^{3}$ Due to the nature of the device, a trajectory method is used and so conformal volumetric treatments are difficult to achieve. Invasive procedures carry a higher risk of infection, and there is also a risk of intracranial hemorrhage from the passage of the instrument.

\section{Conclusions}

This is the first study of its kind to detail the feasibility of MRgFUS for minimally invasive heating of mesial temporal lobe structures. Such an approach could be used in the minimally invasive treatment of temporal lobe epilepsy. This technique potentially avoids the issues of radiation necrosis and edema seen with radiosurgical approaches and avoids the hemorrhagic and target-related complications seen with minimally invasive trajectory-based treatments. Heating of critical skull base structures can be minimized with strategic placement of no-pass regions in the treatment plan using the device's planning software. More work needs to be done in phantoms to optimize a safe and time-efficient treatment algorithm that would be feasible with currently available technology. A pilot study using MRgFUS for the treatment of MTLE should be considered but only undertaken by those with considerable experience with MRgFUS. Treatment of this area of the brain with current technologies requires an in-depth understanding of the device limitations at the treatment envelope extremes.

\section{References}

1. Di Gennaro G, Casciato S, Quarato PP, Mascia A, D’Aniello A, Grammaldo LG, et al: Acute postoperative seizures and 
long-term seizure outcome after surgery for hippocampal sclerosis. Seizure 24:59-62, 2015

2. Dobrakowski PP, Machowska-Majchrzak AK, Labuz-Roszak B, Majchrzak KG, Kluczewska E, Pierzchała KB: MR-guided focused ultrasound: a new generation treatment of Parkinson's disease, essential tremor and neuropathic pain. Interv Neuroradiol 20:275-282, 2014

3. Drane DL, Loring DW, Voets NL, Price M, Ojemann JG, Willie JT, et al: Better object recognition and naming outcome with MRI-guided stereotactic laser amygdalohippocampotomy for temporal lobe epilepsy. Epilepsia 56:101113,2015

4. Elias WJ, Huss D, Voss T, Loomba J, Khaled M, Zadicario E, et al: A pilot study of focused ultrasound thalamotomy for essential tremor. N Engl J Med 369:640-648, 2013

5. Elias WJ, Khaled M, Hilliard JD, Aubry JF, Frysinger RC, Sheehan JP, et al: A magnetic resonance imaging, histological, and dose modeling comparison of focused ultrasound, radiofrequency, and Gamma Knife radiosurgery lesions in swine thalamus. J Neurosurg 119:307-317, 2013

6. Harnof S, Zibly Z, Cohen Z, Shaw A, Schlaff C, Kassel NF: Cranial nerve threshold for thermal injury induced by MRI-guided high-intensity focused ultrasound (MRgHIFU): preliminary results on an optic nerve model. IEEE Trans Ultrason Ferroelectr Freq Control 60:702-705, 2013

7. Hynynen K, Chung AH, Colucci V, Jolesz FA: Potential adverse effects of high-intensity focused ultrasound exposure on blood vessels in vivo. Ultrasound Med Biol 22:193-201, 1996

8. Jeanmonod D, Werner B, Morel A, Michels L, Zadicario E, Schiff G, et al: Transcranial magnetic resonance imagingguided focused ultrasound: noninvasive central lateral thalamotomy for chronic neuropathic pain. Neurosurg Focus 32(1):E1, 2012

9. Malikova H, Kramska L, Vojtech Z, Liscak R, Sroubek J, Lukavsky J, et al: Different surgical approaches for mesial temporal epilepsy: resection extent, seizure, and neuropsychological outcomes. Stereotact Funct Neurosurg 92:372-380, 2014

10. Malikova H, Vojtech Z, Liscak R, Prochazka T, Vymazal $\mathrm{J}$, Mareckova I, et al: Microsurgical and stereotactic radiofrequency amygdalohippocampectomy for the treatment of mesial temporal lobe epilepsy: different volume reduction, similar clinical seizure control. Stereotact Funct Neurosurg 88:42-50, 2010

11. Malikova H, Vojtech Z, Liscak R, Prochazka T, Vymazal J, Vladyka V, et al: Stereotactic radiofrequency amygdalohippocampectomy for the treatment of mesial temporal lobe epilepsy: correlation of MRI with clinical seizure outcome. Epilepsy Res 83:235-242, 2009

12. Mansouri A, Fallah A, McAndrews MP, Cohn M, Mayor D, Andrade D, et al: Neurocognitive and seizure outcomes of selective amygdalohippocampectomy versus anterior temporal lobectomy for mesial temporal lobe epilepsy. Epilepsy Res Treat 2014:306382, 2014

13. McDannold N, Clement GT, Black P, Jolesz F, Hynynen K: Transcranial magnetic resonance imaging- guided focused ultrasound surgery of brain tumors: initial findings in 3 patients. Neurosurgery 66:323-332, 2010

14. Medel R, Monteith SJ, Elias WJ, Eames M, Snell J, Sheehan JP, et al: Magnetic resonance-guided focused ultrasound surgery: Part 2: A review of current and future applications. Neurosurgery 71:755-763, 2012

15. Medvid R, Ruiz A, Komotar RJ, Jagid JR, Ivan ME, Quencer
RM, et al: Current applications of MRI-guided laser interstitial thermal therapy in the treatment of brain neoplasms and epilepsy: a radiologic and neurosurgical overview. AJNR Am J Neuroradiol [epub ahead of print], 2015

16. Monteith S, Sheehan J, Medel R, Wintermark M, Eames M, Snell J, et al: Potential intracranial applications of magnetic resonance-guided focused ultrasound surgery. J Neurosurg 118:215-221, 2013

17. Monteith SJ, Medel R, Kassell NF, Wintermark M, Eames $\mathrm{M}$, Snell J, et al: Transcranial magnetic resonance-guided focused ultrasound surgery for trigeminal neuralgia: a cadaveric and laboratory feasibility study. J Neurosurg 118:319328,2013

18. Ram Z, Cohen ZR, Harnof S, Tal S, Faibel M, Nass D, et al: Magnetic resonance imaging-guided, high-intensity focused ultrasound for brain tumor therapy. Neurosurgery 59:949956, 2006

19. Ramey WL, Martirosyan NL, Lieu CM, Hasham HA, Lemole GM Jr, Weinand ME: Current management and surgical outcomes of medically intractable epilepsy. Clin Neurol Neurosurg 115:2411-2418, 2013

20. Régis J, Rey M, Bartolomei F, Vladyka V, Liscak R, Schröttner O, et al: Gamma knife surgery in mesial temporal lobe epilepsy: a prospective multicenter study. Epilepsia 45:504-515, 2004

21. Shim KW, Chang JH, Park YG, Kim HD, Choi JU, Kim DS: Treatment modality for intractable epilepsy in hypothalamic hamartomatous lesions. Neurosurgery 62:847-856, 2008

22. Suffredini G, Levy LM: MR-guided, focused ultrasound: applications to essential tremor and other neurologic conditions. AJNR Am J Neuroradiol 35:829-831, 2014

23. Vojtech Z, Vladyka V, Kalina M, Nespor E, Seltenreichová $\mathrm{K}$, Semnická J, et al: The use of radiosurgery for the treatment of mesial temporal lobe epilepsy and long-term results. Epilepsia 50:2061-2071, 2009

24. Willie JT, Laxpati NG, Drane DL, Gowda A, Appin C, Hao $\mathrm{C}$, et al: Real-time magnetic resonance-guided stereotactic laser amygdalohippocampotomy for mesial temporal lobe epilepsy. Neurosurgery 74:569-585, 2014

25. Wintermark M, Druzgal J, Huss DS, Khaled MA, Monteith $\mathrm{S}$, Raghavan $\mathrm{P}$, et al: Imaging findings in MR imaging-guided focused ultrasound treatment for patients with essential tremor. AJNR Am J Neuroradiol 35:891-896, 2014

\section{Disclosures}

Dr. Monteith reports direct stock ownership in Cerevast Therapeutics. Dr. Kassell reports an ownership interest in InSightec.

\section{Author Contributions}

Conception and design: Monteith, Snell, Kassell, Gwinn. Acquisition of data: Monteith, Snell, Gwinn. Analysis and interpretation of data: Monteith, Snell, Kassell, Gwinn. Drafting the article: Monteith, Snell. Critically revising the article: all authors. Reviewed submitted version of manuscript: Monteith. Approved the final version of the manuscript on behalf of all authors: Monteith.

\section{Correspondence}

Stephen Monteith, Swedish Neuroscience Institute, 550 17th Ave., Ste. 110, Seattle, WA 98122. email: stephen.monteith@ gmail.com. 